\title{
Neurolaw and Direct Brain Interventions
}

\author{
Nicole A Vincent
}

Published online: 6 June 2012

(C) The Author(s) 2012. This article is published with open access at Springerlink.com

\begin{abstract}
This issue of Criminal Law and Philosophy contains three papers on a topic of increasing importance within the field of "neurolaw"-namely, the implications for criminal law of direct brain intervention based mind altering techniques (DBI's). To locate these papers' topic within a broader context, I begin with an overview of some prominent topics in the field of neurolaw, where possible providing some references to relevant literature. The specific questions asked by the three authors, as well as their answers and central claims, are then sketched out, and I end with a brief comment to explain why this particular topic can be expected to gain more prominence in coming years.
\end{abstract}

Keywords Neurolaw $\cdot$ Overview $\cdot$ Direct brain interventions

\section{Neurowhat?}

In terms of its history, neurolaw is a relatively recent field. Although discussion of many of the issues still at the heart of current debates dates back to the early 1990s (Martell 1992), much of the activity in this field has taken place during the past decade. In this respect this field's youthfulness reflects the relatively-recent advances made within the field of cognitive neuroscience, in large degree made possible by the development of powerful new diagnostic neuroimaging techniques_ones with fancy acronyms like CAT, PET, SPECT, MRI, fMRI and DTI, etc. (Jones et al. 2009) - that made it possible to study the structure and function of living brains in situ, with hitherto-unprecedented detail, without ever having to reach for cranial saws, drills and scalpels. In terms of content, I find it useful to categorize the topics discussed in this field under four headings-scientific discoveries, diagnostic techniques, intervention techniques, and legal procedure-though this categorization is by no means conventional nor prescriptive (for other categorizations see e.g.

\footnotetext{
N. A Vincent

Philosophy Department, Macquarie University, Sydney, NSW, Australia

N. A Vincent $(\bowtie)$

Philosophy Department, TU Delft, Delft, The Netherlands

e-mail: nicole.vincent@mq.edu.au
} 
Eagleman 2008; Gazzaniga 2008; Goodenough and Tucker 2010; Lekovic 2008; Mobbs et al. 2007; Prado and Patterson 2010).

First, scientific discoveries about the nature of human cognition and volition have motivated a number of discussions. For instance, much ink has been spilled debating whether, in light of emerging evidence that the brain is just another mechanism that operates according to laws of nature, any room remains for concepts like responsibility and practices like punishment (Greene and Cohen 2004; Morse 2006). Similar-sounding doubts have sprung from a different angle-empirical studies suggest that humans have much less conscious control over their thought and action than we typically take ourselves to have. This has been taken by some to entail that the law should cut everyone more slack, since its expectations are founded on unrealistic and even patently false assumptions about what humans are actually capable of (Levy forthcoming; Dahan-Katz forthcoming; Davies forthcoming). Research into the role of emotion in moral judgment is cited to criticise the law's conception of rationality-debates about whether psychopaths should be excused on account of their affective deficits come to mind (Blair 2007; Fine and Kennett 2004; Haji 2010). And some suggest that neuroscience might help us to design more effective and efficient laws by providing greater insight into what actually motivates human behaviour (Jones 2004). The underlying idea here is that to the extent that the law regulates human behaviour, and the brain plays a key role in generating that behaviour, better knowledge of the brain will lead to better-designed laws.

Second, new diagnostic techniques hold out the promise of helping to address a number of practical legal problems. For instance, perhaps improved brain-based lie detection techniques can be developed that check directly in the brain for signs of deception or of familiarity with "guilty knowledge" (i.e. evidence that only the perpetrator would recognize) (see the collection of papers in Bizzi et al. 2009). Others raise the possibility that some diagnostic techniques might eventually provide more objective and perhaps even foolproof ways of individually assessing people's true mental capacities and thus their responsibility (Vincent 2010; Hirstein and Sifferd 2011). And yet others ponder whether this new science and technology might help us to better predict people's propensities, dangerousness and recidivism (Greely 2009; Kaplan 2009) - putting it crudely, the underlying idea is that there might be tell-tale features of certain people's brains that correlate with dangerousness and criminality.

Third, in addition to diagnostic techniques, neuroscientists also use a range of intervention techniques, in particular DBIs. ${ }^{1}$ Beyond the cranial saw, drill and scalpel, there are also gamma ray knives which focus multiple beams of radiation on a single point to destroy tissue where the rays intersect without needing to crack open the skull or to cut through intervening tissue to get to a target site, as well as deep brain stimulation, radioisotope therapy, transcranial magnetic stimulation, electroconvulsive therapy, and an increasing(ly profitable) range of psychopharmaceuticals to name just a few DBIs. With increased

\footnotetext{
${ }^{1}$ Direct brain intervention based techniques are typically contrasted with what at least intuitively seem like more indirect ways of changing people's minds-e.g. cognitive behavioural therapy or even just talking to another person. But as Neil Levy points out, it can be very difficult to put a finger on precisely what is meant to be morally significant about this distinction. After all, if both methods involve changing another's mind in the same way (i.e. with the same outcome), then why should one method be treated differently than the other (2007:62-9)? Furthermore, as Jan Christoph Bublitz and Reinhard Merkel (this issue) point out, it may sometimes even be difficult to decide whether to categorize a given intervention-e.g. subliminal advertising - as an instance of direct or indirect intervention. Nevertheless, for our purposes Bublitz and Merkel's suggestion that " $[\mathrm{r}]$ oughly one could say that indirect interventions are inputs into the cognitive machinery our minds are adapted to process, whereas direct interventions change the cognitive machinery itself" nicely captures the intuitive idea that this distinction is meant to capture.
} 
knowledge of how the brain functions comes the promise of developing better-targeted treatments for pathological brain conditions like Alzheimer's and Parkinson's disease. However, what has roused interest from neurolaw researchers is the possibility that DBIs might be developed for use not just in a clinical setting, but to provide (e.g.) treatments for brain-based causes of (mental disorders correlated with) criminal and disfavoured behaviour (Bomann-Larsen 2011; Greely 2008), ways of disabling witnesses' ability to lie and deceive (Coukell 2006; Rosen 2007), drugs that enhance witness memory (Vedder and Klaming 2010), and a range of other cognitive enhancing drugs which raise numerous political and legal issues (Farah et al. 2004; Glannon 2008, 2011; Vincent forthcoming).

Fourthly, as to legal procedure, discussion has also focused on whether existing criminal procedure and rules can accommodate such new scientific evidence and intervention techniques. For instance, do existing rules allow this high-tech evidence to be adduced at trial, and if so then at which stage? The Federal Rules of Evidence and the Daubert standard come to mind for the North American context (Tovino 2007), and in Australia the Commonwealth Evidence Act 1995 and similar State acts provide pertinent examples (Houston and Vierboom 2012). Who is permitted to bring such evidence to trial and for what purposes can it be used-e.g. by the prosecution to establish guilt, or only by the defence to counter allegations of guilt? What role should expert testimony, which is often needed to interpret such evidence, be allowed to play, and what principles should judges use when experts disagree about the value of particular evidence? Assuming that such evidence should at least sometimes be admissible, what standing should it have in relation to other kinds of evidence-e.g. should brain-based lie detection results trump witness testimony and the jury's role in credibility assessments or vice versa (Chandler 2010)? How should such evidence and testimony be treated - for instance, if mind reading ever becomes a reality, ${ }^{2}$ would it constitute and be governed by rules pertaining to physical evidence, or would it be an instance of and thus be governed by rules pertaining to testimonial evidence (Farahany 2012)? Might the use of such techniques to gather this evidence impinge on existing rights-e.g. would brainbased mind reading techniques infringe the right to remain silent (Fox 2011)? And how about the legality of using DBIs to achieve the various aims of the criminal law?

The above list of topics is only intended to convey the flavour of some of the work that is done in this field. Also, importantly, a recurring theme is that much of what is discussed is in many cases aspirational-i.e. neither the science nor the technology or the techniques are yet sufficiently advanced, tested or polished to be rolled out into courtrooms and used in real life cases. Most of these discussions should therefore be viewed as hypothetical explorations, as investigations into what could or should be done once the science, technology and techniques are ready for prime time. However, some actual legal cases have already been affected, and in particular two cases from Italy come to mind. In one, evidence that a convicted murderer carried an allele for the gene MAOA which, when combined with a violent upbringing, is correlated with higher degrees of aggressiveness, was adduced to reduce the length of the prison sentence to 9 years and 2 months (a reduction of approximately 3 years) (Feresin 2009). In the other case, both genetic and neuroscientific evidence were relied upon by the court to mitigate the sentence of a 28 year old woman who first killed her sister, and then attempted to kill her mother in order to

\footnotetext{
${ }^{2}$ A technique recently described by Nishimoto et al. (2011) received much media coverage and scientific attention after demonstrating the feasibility of decoding what movies were viewed by subjects from scans of their brain activity obtained using current fMRI technology. Perhaps a future iteration of such technology can help courts to decode not merely what images and movies are being viewed by subjects, but also what images they remember or imagine.
} 
cover up her crime, from life to 20 years (Farisco and Petrini 2012). Nita Farahany's pioneering work at the Vanderbilt Law School shows a groundswell of cases in the USA in recent years in which neuroscientific evidence is cited and relied upon in novel ways, and similar projects that catalogue and analyse the appearance of such cases are also currently under way in Australia, Canada, Germany, Italy, The Netherlands and the United Kingdom. The significance of neurolaw was recently recognised when The Royal Society (2011:vi) released their findings about neuroscience and the law in which they recommended (among other things) that "[a]n international meeting should take place every 3 years to bring together those working across the legal system with experts in neuroscience and related disciplines" and that "[u]niversity law degrees should incorporate an introduction to the basic principles of how science is conducted and to key areas of science such as neuroscience and behavioural genetics".

\section{This Special Issue's Papers}

The three papers contained in this special issue of Criminal Law and Philosophy address questions that straddle the third and fourth groups of topics discussed above.

Jan Christoph Bublitz and Reinhard Merkel ask the broad normative question: In what ways should it be permissible to change other people's minds? Changing one another's minds through conversation or through other standard forms of communication is usually deemed uncontroversial. But how about the following scenarios? Should fast food outlets be allowed to add substances like Gherlin to their food and drinks, or to spray substances into the air surrounding their restaurants, to induce desires for their products in customers and in passers-by in order to boost sales? What if an online store used subliminal advertising that primed customers with a preference for particular products-should that be permitted? Should employers be allowed to add substances to their employees' tea, coffee or other beverages-e.g. psychostimulants - to increase their productivity? What if a player in a game of poker sprayed the odourless substance Oxytocin around the table to make other players more trusting and thus less likely to notice when she is bluffing? If governments could convince the public to get behind laudable aims like reducing greenhouse gas emissions through the use of subliminal television advertisements, should this be permitted? The point is that the substances and techniques involved might have negligible or even no adverse physical effects-i.e. health or physical injury might not be an issuebut it still seems like at least some of these practices should be prohibited (or at least controlled) qua illegitimate (or otherwise-troublesome) interferences with others' mental integrity. Bublitz and Merkel write that "[w]hile legal systems have developed detailed rules of permissible conduct with bodies, have defined exceptions, counter exceptions, conditions of consent, acceptable risks and compensable harm, legal doctrines over conduct with another's mind are hard to find and strikingly underdeveloped." However, they contend that there are important reasons to distinguish between different ways of altering other people's minds-for instance, while "marital infidelity generating severe mental suffering for the partner" may not be prohibited by the criminal law, "inducing the "same pain' through a different means, say, a lovesickness pill, triggering identical neuronal activity and evoking the identical phenomenal experience of suffering should be impermissible". Bucking the trend in current neuroethics literature-for instance, Neil Levy's "parity thesis" according to which direct and indirect interventions should often be treated on a par with one another (Levy 2007:37-44), and Hank Greely's claim that there is "no qualitative difference between acting directly to change a criminal's brain... and acting 
indirectly... to achieve similar ends" (2008:1134) — Bublitz and Merkel argue that from a legal perspective there are compelling reasons to retain and take heed of this distinction. In light of such reasons, they propose that the law should recognize the human right to mental liberty, and to protect this right they propose elements of a new criminal offence proscribing severe interventions into other minds.

While the focus of Bublitz and Merkel's paper is broad-i.e. their concern is with how anyone in society should be permitted to change anyone else's mind-Elizabeth Shaw asks a more narrowly-focused normative question about the law's use of DBIs, namely: Under what circumstances might it be permissible to use DBIs to rehabilitate convicted criminals? Shaw begins by noting that despite the massive cost of keeping offenders incarcerated, incarceration has a dismal record of rehabilitating offenders, with as many as seventy per cent returning to prison shortly following their release. Given the shortcomings of incarceration as a rehabilitative tool, and given that advances in neuroscience promise more effective ways of altering human behaviour through DBIs, this raises the question of whether the law should avail itself of such techniques. Shaw considers two explanations for why we might recoil from this suggestion. The first explanation which she considers is that altering people's minds through DBIs might undermine their free will, conceived in broadly compatibilist terms. However, she argues that philosophical compatibilism ${ }^{3}$ lacks the theoretical resources to explain why such interventions might be problematic-in fact, on her account compatibilists would ultimately have to accept that a person whose mind had been thoroughly manipulated in certain ways would possess rather than lack free will - and for this reason she looks elsewhere to explain why we might recoil from using DBIs. According to Shaw, the best way to make sense of our concerns is by focusing on the distinction between those techniques that would merely enhance the offender's "capacity responsibility" and those that would attempt to make offenders more responsible in the "virtue" sense. The former type of intervention would attempt to strengthen mental capacities such as understanding and self-control which are necessary for agency and participation in moral discourse with other members of the moral community, whereas the latter would aim to instil in them particular values about what is right and wrong or corresponding preferences. Enhancing virtue responsibility is unacceptable on her account because it would objectify offenders-i.e. they would be treated as fundamentally different from the rest of society, as creatures who are beyond redemption with whom we cannot engage in moral dialogue, and who must thus be re-molded like mere objects-but also because it would silence offenders and diminish the opportunities for society to learn when its views, rather than the views of the offender, are what stand in need of revision. In contrast, enhancing offenders' capacity responsibility would give them the tools that they need to engage in moral dialogue and practical reasoning through which they can, if they so choose, re-shape their own values.

Finally, my own paper investigates whether three aims of the criminal law-namely, justice, reform and therapy — can be promoted through the use of DBIs. DBI-based mental capacity restoration techniques - for instance, psycho-active drugs-are sometimes used in criminal cases to promote the aims of justice. For instance, they might be used to restore a person's competence to stand trial in order to assess the degree of their responsibility for what they did, or to restore their competence for punishment so that we can hold them

\footnotetext{
3 This is a theoretical approach according to which free will and responsibility hinge not on whether our behaviour is caused (or determined in some other way) or not, but on whether it is caused through mechanisms in virtue of which we possess the right kinds of mental capacities-i.e. those, whichever they are, which are required for moral agency.
} 
responsible for their crime. Some also suggest that such interventions might be used in criminal legal contexts for therapy or reform-i.e. to make non-responsible and irresponsible people more responsible. However, I argue that such interventions may at least sometimes fail to promote these responsibility-related aims of the criminal law because, at least on some accounts, responsibility hinges on other factors than just what mental capacities a person has-in particular, it also hinges on such things as authenticity, personal identity, and mental capacity ownership_and there are compelling reasons to suspect that some ways of restoring mental capacity (in particular DBIs) may adversely affect these other factors. My concerns in this regard spring from two sources. First, I cite mounting empirical evidence that DBIs can have profound effects on their subjects' character and personality with similarly profound effects on qualitative aspects of their personal identity, and these effects raise problems for attributions and impositions of responsibility. Second, I also argue that the very same features that make DBIs attractive within the context of the criminal law-i.e. their speed of action, their touted effectiveness, and the fact that little cooperation or even input is needed from the person being treated to have their effect-paradoxically also raise concerns about authenticity, personal identity and mental capacity ownership which, alongside mental capacity, are also important factors when it comes to responsibility. Put one way, my central claim is that what might suffice for the restoration of competence might not suffice for the restoration of responsibility. Put another way, I claim that although responsibility does indeed track mental capacity, we should be wary of assuming that responsibility will also track restored mental capacities - in particular, ones that have been restored through DBIs.

\section{Timeliness of this Topic}

Viewed from one perspective, DBIs do not raise new issues. In a recent opinion piece for Clinical Pharmacology \& Therapeutics, Hank Greely observes that "many of the[se questions] were raised 40 years ago, during an earlier period of concern about what was then called "mind control"' (Greely 2012:165; also see Lewis 1963). Ice-pick lobotomies, surgical and chemical castration for sex offenders and paedophiles, and forced medication to make people competent for trial and for execution raise familiar issues. However, as Greely also points out, what has changed over the past 40 years is that "[n]ow... neuroscience is likely to provide real direct brain interventions [for instance] to treat disfavored behaviours, forcing us to decide whether, when, and how such interventions may be used" (2012:164-5).

Because of the order in which progress in this field is made-diagnostic techniques and technologies must first be created by scientists and engineers; these can then be used in neuroscientific studies and experiments that contribute to the growth of knowledge; and this knowledge can eventually be drawn upon by other scientists, engineers and medical researchers and practitioners to develop well-targeted interventions ${ }^{4}$ - in the coming years we can expect an increasing number of DBIs to be developed, and that gives this topic a renewed sense of urgency. However, another thing that has changed in the intervening years is that we have acquired those 40 years worth of experience with brilliant successes

\footnotetext{
4 This is an idealized picture, since often a much more opportunistic hit-and-miss approach is taken in the development of new psychopharmaceuticals. Nevertheless, the basic idea-i.e. that a better understanding of the brain-based correlates and causes of mental disorders can help us to develop better treatments for those disorders—-still holds.
} 
and dismal failures at using DBIs to alter people's minds, and such experience can reveal important oversights and foibles in our earlier thinking about this topic.

Greely suggests that it is not too early to talk about these issues (2012:165), and I agree. They should be discussed and debated well before existing techniques and technologies are further refined-before yet further intervention techniques are developed — to avoid finding ourselves in a political climate where crime reduction and budget cuts are on the electoral agenda, with temptingly effective tools at our disposal but no clear ethical or policy directives for their use. This may help us to avoid the tragedies of psychosurgery, and to steer clear of scenarios like those depicted by Burgess (2000) in the novel A Clockwork Orange, later made into a movie with the same title by Stanley Kubrick. This may also help to funnel resources towards research and development of those interventions which are (even at a conceptual level) likely to achieve their aims, and which (at a normative level) are likely to be permitted and maybe even endorsed, recommended, requested and required.

I hope that the papers in this special issue stimulate further discussion of this topic.

Open Access This article is distributed under the terms of the Creative Commons Attribution License which permits any use, distribution, and reproduction in any medium, provided the original author(s) and the source are credited.

\section{References}

Bizzi, E., Hyman, S. E., et al. (2009). Using imaging to identify deceit: Scientific and ethical questions. Cambridge, MA: American Academy of Arts and Sciences.

Blair, R. J. R. (2007). What emotional responding is to blame it might not be to responsibility. Philosophy, Psychiatry \& Psychology, 14(2), 149-151.

Bomann-Larsen, L. (2011). Voluntary rehabilitation? on neurotechnological behavioural treatment, valid consent and (In)appropriate offers. Neuroethics (OnlineFirst). doi:10.1007/s12152-011-9105-9.

Burgess, A. (2000). A clockwork orange (with an introduction by Blake Morrison). London: Penguin Books Ltd.

Chandler, J. A. (2010). Reading the judicial mind: Predicting the courts' reaction to the use of neuroscientific evidence for lie detection. Dalhousie Law Journal, 33(1), 85-116.

Coukell, A. (2006). No more lies. Proto: 32-7.

Dahan-Katz, L. (forthcoming). The implications of heuristics and biases research on moral and legal responsibility: A case against the reasonable person standard. Neuroscience and Legal Responsibility. N. Vincent, OUP.

Davies, P. (forthcoming). Skepticism concerning human agency: Sciences of the self vs. 'voluntariness' in the law. In N. Vincent (Ed.), Neuroscience and Legal Responsibility. OUP.

Eagleman, D. M. (2008). Neuroscience and the Law. Houston Lawyer, 16(6), 36-40.

Farah, M. J., Illes, J., et al. (2004). Neurocognitive enhancement: what can we do and what should we do? Nature Reviews Neuroscience, 5(5), 421-425.

Farahany, N. A. (2012). Incriminating thoughts. Stanford Law Review, 64, 351-408.

Farisco, M., \& Petrini, C. (2012). The impact of neuroscience and genetics on the law: A recent Italian case. Neuroethics OnlineFirst: 1-3. doi:10.1007/s12152-012-9152-x.

Feresin, E. (2009). Lighter sentence for murderer with 'bad genes'. Nature News. doi:10.1038/news. 2009.1050.

Fine, C., \& Kennett, J. (2004). Mental impairment, moral understanding and criminal responsibility: Psychopathy and the purposes of punishment. International Journal of Law and Psychiatry, 27(5), 425-443.

Fox, D. (2011). The right to silence protects mental control. Law and Neuroscience, Current Legal Issues, 13. M. Freeman. Oxford, UK, OUP: 335-66.

Gazzaniga, M. S. (2008). The law and neuroscience. Neuron 60(November 6): 412-415.

Glannon, W. (2008). Psychopharmacological enhancement. Neuroethics, 1(1), 45-54.

Glannon, W. (2011). Diminishing and enhancing free will. AJOB Neuroscience, 2(3), 15-26. 
Goodenough, O. R., \& Tucker, M. (2010). Law and cognitive neuroscience. Annual Review of Law and Social Science, 6, 61-92.

Greely, H. T. (2008). Neuroscience and criminal justice: Not responsibility but treatment. University of Kansas Law Review, 56, 1103-1138.

Greely, H. T. (2009). Who knows what evil lurks in the hearts of men?: Behavioral genomics, neuroscience, criminal law, and the search for hidden knowledge. The Impact of Behavioral Sciences on Criminal Law. N. A. Farahany. New York, NY, OUP: 161-79.

Greely, H. T. (2012). Direct brain interventions to treat disfavored human behaviors: Ethical and social issues. Clinical Pharmacology and Therapeutics, 91(2), 163-165.

Greene, J., \& Cohen, J. D. (2004). For the law, neuroscience changes nothing and everything. Philosophical Transactions of the Royal Society of London: 1775-1785. doi:10.1098/rstb.2004.1546.

Haji, I. (2010). Psychopathy, ethical perception, and moral culpability. Neuroethics, 3(2), 135-150.

Hirstein, W., \& Sifferd, C. (2011). The legal self: Executive processes and legal theory. Consciousness and Cognition, 2, 156-171.

Houston, L., \& Vierboom, A. (2012). Neuroscience and law: Australia. International Neurolaw. T. M. Spranger. Heidelberg, DE, Springer: 11-42.

Jones, O. D. (2004). Law, evolution and the brain: applications and open questions. Law and the Brain. S. Zeki and O. R. Goodenough. New York, Oxford University Press: 57-75.

Jones, O. D., \& Buckholtz, J. W., et al. (2009). Brain imaging for legal thinkers: A guide for the perplexed. Stanford Technology Law Review: 5. Accessed on May 29, 2012 at http://stlr.stanford.edu/ pdf/jones-brain-imaging.pdf.

Kaplan, J. (2009). Misinformation, misrepresentation, and misuse of human behavioral genetics research. The Impact of Behavioral Sciences on Criminal Law. N. A. Farahany. New York, NY, OUP: 45-80.

Lekovic, G. P. (2008). Neuroscience and the law. Surgical Neurology, 69, 99-101.

Levy, N. (2007). Neuroethics: Challenges for the 21st century. Cambridge University Press: Cambridge, UK.

Levy, N. (forthcoming). Moral responsibility and consciousness: two challenges, one solution. Neuroscience and Legal Responsibility. N. Vincent, OUP.

Lewis, C. S. (1963). The humanitarian theory of punishment. Res Judicatae, 6, 224-230.

Martell, D. A. (1992). Forensic neuropsychology and the criminal law. Law and Human Behavior, 16(3), 313-336.

Mobbs, D., Lau, H. C., et al. (2007). Law, responsibility, and the brain. PLoS Biology, 5(4), 693-700.

Morse, S. J. (2006). Brain overclaim syndrome and criminal responsibility: A diagnostic note. Ohio State Journal of Criminal Law, 3, 397-412.

Nishimoto, S., Vu, A. T., et al. (2011). Reconstructing visual experiences from brain activity evoked by natural movies. Current Biology, 21(19), 1641-1646.

Prado, M. S., \& Patterson, D. (2010). Philosophical foundations of law and neuroscience. University of Illinois Law Review, 4, 1211-1250.

Rosen, J. (2007). The brain on the stand. The New York Times.

The Royal Society. (2011). Brain waves module 4: Neuroscience and the law. London, UK: The Royal Society.

Tovino, S. A. (2007). Functional neuroimaging and the law: Trends and directions for future scholarship. The American Journal of Bioethics, 7(9), 44-56.

Vedder, A., \& Klaming, L. (2010). Human enhancement for the common good—using neurotechnologies to improve eyewitness memory. AJOB Neuroscience, 1(3), 22-33.

Vincent, N. (2010). On the relevance of neuroscience to criminal responsibility. Criminal Law and Philosophy, 4(1), 77-98.

Vincent, N. (forthcoming). Enhancing responsibility. In N. Vincent (Ed.), Neuroscience and Legal Responsibility. OUP. 